\title{
Comitê de Auditoria versus Conselho Fiscal Adaptado: a visão dos analistas de mercado e dos executivos das empresas que possuem ADRs
}

\section{Audit Committee versus Adapted Fiscal Council: the point of view of market analysts and executives of companies with ADRs}

\section{Fernanda Furuta}

Professora Doutora da Fundação Instituto de Administração * E-mail:

fernandafuruta@yahoo.com.br

\begin{abstract}
Ariovaldo dos Santos
Professor Doutor do Departamento de Contabilidade e Atuária da Faculdade de Economia, Administração e Contabilidade da Universidade de São Paulo * E-mail: arisanto@usp.br
\end{abstract}

Recebido em 03.04.2010 * Aceito em 28.05.2010 * $2^{\mathrm{a}}$ versão aceita em 07.07.2010

\section{RESUMO}

Este estudo tem como objetivo obter a opinião dos executivos das empresas que operam no Brasil e negociam seus títulos no mercado norte-americano e dos analistas de mercado sobre a formação do Comitê de Auditoria ou do Conselho Fiscal adaptado. Para isso, foram aplicados questionários e realizadas entrevistas. A maioria dos executivos das empresas que formaram o Comitê de Auditoria apontaram que o nível de governança corporativa foi um dos fatores que mais influenciou na decisão de se formar um ou outro órgão. Por outro lado, a maioria dos executivos das empresas que formaram o Conselho Fiscal adaptado indicaram, além do nível de governança corporativa, o fato de ser auditada por uma das Big4 e a classificação da empresa conforme o valor agregado de mercado como fatores que influenciaram nas suas decisões. Não houve consenso de opiniões quanto ao Conselho Fiscal ser mais adaptável que o Comitê de Auditoria ao ambiente de negócios brasileiros, se as funções dos dois órgãos são distintas e se os custos associados à formação do Comitê de Auditoria são ou não relevantes. Assim, pode-se concluir que, em alguns aspectos, as percepções dos analistas de mercado e dos executivos das empresas são bastante diferentes.

Palavras-Chave: Comitê de Auditoria. Conselho Fiscal adaptado.

\section{ABSTRACT}

The aim of this study was to obtain the opinion of executives working in companies that companies that operate in Brazil and negotiate their titles in the North-American market and the opinion of market analysts. For that, we used questionnaires and made interviews. The majority of executives working in companies with an Audit Committee pointed out the level of Corporate Governance as one of the factors that most influenced the decision to establish either of the agencies. On the other hand, according to the majority of executives working in 
companies with an adapted Fiscal Council, the level of Corporate Governance, in addition to the fact that the company was audited by one of the Big4, and the company's classification according to the Aggregate Worldwide Market Value, were factors that influenced their decisions. There was no consensus of opinions among company executives and market analysts regarding a Fiscal Council being more adaptable to the Brazilian business environment than an Audit Committee, both in terms of the role of each entity being distinct and in terms of the costs associated with building an Audit Committee. Thus, we can conclude that in some cases, the point of view of analysts is different than that of company executives.

Keywords: Audit Committee. Adapted Fiscal Council.

\section{INTRODUÇÃO}

A crescente preocupação das empresas em relação à governança corporativa, principalmente após as fraudes ocorridas no início do século 21, muitas delas atribuídas a falhas de controle relacionadas às "práticas contábeis" e, mais recentemente, o problema com derivativos ocorridos em 2008 que, no Brasil, envolveram grandes empresas como a Aracruz e a Sadia, torna este estudo de extrema relevância, já que um dos pontos relacionados com a governança corporativa é a formação do Comitê de Auditoria.

O Congresso Norte-Americano, em resposta imediata à sequência de escândalos, aprovou, em julho de 2002, a Lei Sarbanes-Oxley, também conhecida como Sox. Uma das imposições da Sox, que afetou as empresas estrangeiras, está relacionada à implementação de Comitês de Auditoria. Muitos países têm incentivado as empresas a constituírem esse órgão com a premissa de que por meio dele é possível melhorar alguns aspectos relacionados à governança corporativa.

A Securities and Exchange Comission (SEC) estabeleceu que o prazo para as companhias estrangeiras, com registro no mercado de capitais norte-americano, cumprirem a Seção 301 (referente à constituição dos Comitês de Auditoria) da Lei Sarbanes-Oxley era 31 de julho de 2005. As empresas que operam no Brasil e têm seus títulos negociados no mercado norte-americano tiveram que se adequar a essa nova situação dentro do prazo estabelecido.

Para o caso brasileiro, a SEC deu a opção para as empresas formarem o Comitê de Auditoria ou utilizarem o Conselho Fiscal adaptado às funções do Comitê. As opiniões sobre a implantação do Comitê de Auditoria ou a transformação do Conselho Fiscal adaptando-o às funções daquele Comitê podem ser bastante divergentes. 
Do ponto de vista conceitual, este trabalho partiu do pressuposto de que quanto maior o custo de agência, maior a assimetria de informação entre agente e principal. Consequentemente, maior a necessidade de monitoramento e, assim, maior a chance de a empresa ter um Comitê de Auditoria (COLLIER, 1993; MENON; WILLIAMS, 1994; PINCUS et al., 1989; PIOT, 2004; RAINSBURY et al., 2008; TURLEY; ZAMAN, 2004).

Assim, tendo como base as empresas que operam no mercado brasileiro e que possuem American Depositary Receipts (ADRs), este estudo tem como objetivo obter a opinião e as percepções dos executivos dessas empresas e dos analistas de mercado quanto à formação do Comitê de Auditoria ou do Conselho Fiscal Adaptado.

\section{REFERENCIAL TEÓRICO}

O Comitê de Auditoria, conforme a Seção 301 da Sox, é o responsável direto pela contratação, compensação e supervisão da empresa independente que irá preparar os relatórios de auditoria e trabalhos relacionados, sendo, também, o responsável pela resolução de quaisquer conflitos que possam existir sobre relatórios contábeis entre a administração e os auditores independentes. Além disso, o Comitê pode criar procedimentos para receber, processar e tratar das reclamações e denúncias confidenciais e anônimas recebidas pelos funcionários sobre contabilidade, controles internos contábeis ou assuntos relacionados à auditoria. O Comitê de Auditoria tem, igualmente, a autoridade de contratar consultores independentes, caso seja necessário.

A CVM e a Associação Brasileira das Companhias Abertas (ABRASCA), em 7 de março de 2003, encaminharam à SEC uma solicitação para que as empresas que operam no Brasil e estivessem sob a regulação da Sox pudessem substituir o Comitê de Auditoria pelo Conselho Fiscal, órgão já existente no Brasil. Assim, seria evitada a duplicidade de funções, custos e ineficiências como também possíveis conflitos de poderes e obrigações. A SEC aceitou o pedido e o Conselho Fiscal pode, então, adaptar suas funções às de um Comitê de Auditoria no Brasil.

Em setembro de 2002, o Instituto Brasileiro de Governança Corporativa (IBGC) já tinha efetuado uma revisão do Código de Melhores Práticas de Governança Corporativa e, naquela ocasião, recomendava que todas as companhias implementassem o Comitê de Auditoria. Em outubro de 2009, o IBGC criou o "Guia de Orientação para Melhores Práticas de Comitês de Auditoria" com o objetivo de auxiliar a instituição e o funcionamento de Comitês de Auditoria nos Conselhos de Administração nas organizações. 
O Conselho Monetário Nacional (CMN) e o Conselho Nacional de Seguros Privados (CNSP), na Resolução n. 3.198/2004, requerem que os conglomerados financeiros e as sociedades seguradoras, de capitalização e entidades abertas de previdência complementar constituam Comitês de Auditoria. A CVM não exige a constituição de Comitê de Auditoria para as companhias que negociam seus títulos no mercado aberto de valores, mas recomenda fortemente essa prática.

Apesar da expectativa de que o Comitê de Auditoria possibilite uma maior transparência nas atividades sociais das empresas, os reguladores, órgãos governamentais e pesquisadores de muitos países têm questionado sobre a efetividade desses Comitês e sua contribuição para a governança corporativa. As falhas de controles corporativos, divulgadas, principalmente, a partir dos anos 2000, envolvendo fraudes, contabilidade inconsistente e falha nos controles internos, forneceram evidências que suportam a preocupação quanto à adequação do monitoramento feito pelos Comitês de Auditoria (TURLEY; ZAMAN, 2004). Alguns críticos apontam que o Comitê de Auditoria da Enron, instalado de forma opcional quando não existia a exigência imposta pela SOX, era formado por seis membros altamente qualificados e, mesmo assim, eles não foram capazes de identificar as irregularidades praticadas pela empresa (FELO et al., 2003).

Diversos estudos (ADAMS, 1997; BRADBURY, 1990; COLLIER, 1993; COLLIER; GREGORY, 1999; MENON; WILLIAMS, 1994; PINCUS et al., 1989; PIOT, 2004; RAINSBURY et al., 2008) analisaram a formação do Comitê de Auditoria sob a abordagem da teoria da agência (FAMA; JENSEN, 1983; JENSEN; MECKLING, 1976). Esses estudos partiram do pressuposto de que o Comitê de Auditoria é um mecanismo efetivo para redução dos custos de agência.

Uma vez que o nível de monitoramento pode ser aumentado com a formação do Comitê de Auditoria, então, a demanda por Comitês de Auditoria deveria ser maior em situações de maior custo de agência. Segundo Pincus et al. (1989), o estabelecimento de um Comitê de Auditoria fornece um canal de comunicação entre o Conselho de Administração e os auditores externos e internos. Os Comitês de Auditoria asseguram a qualidade da auditoria e melhoram a eficiência do monitoramento (COLLIER, 1993, p. 423).

Chow (1982) e Watts e Zimmerman (1986) forneceram evidências de que as empresas adotam, voluntariamente, a auditoria externa em situações de alto custo de agência. Bradbury (1990) confirma que os Comitês de Auditoria, dessa forma, serão voluntariamente empregados em situações de alto custo de agência. Além disso, o Comitê de Auditoria pode 
minimizar as escolhas contábeis oportunas já que sua função inclui revisar os métodos contábeis e suas mudanças (BRAIOTTA, 1981, p. 10).

A possibilidade dada pela SEC às empresas que operam no Brasil para a adaptação de seu Conselho Fiscal às funções de um Comitê de Auditoria trouxe discussões sobre como melhor se adequar à legislação norte-americana. Assim, torna-se importante compreender o papel de cada um desses órgãos na organização.

O Conselho Fiscal é um órgão de fiscalização da própria gestão da companhia, eleito pela Assembleia Geral dos acionistas. Sua composição e funcionamento; requisitos, impedimentos e remuneração, bem como competência, emissão de pareceres, deveres e responsabilidades estão definidos no capítulo XIII da Lei nº 6.404/76. O Conselho Fiscal é um órgão de existência obrigatória, mas de funcionamento não permanente, devendo ser instalado a pedido dos acionistas.

Dentre as competências do Conselho Fiscal, definidas no artigo $\mathrm{n}^{\circ} 163$ da referida Lei, estão a fiscalização dos atos dos administradores, opinião sobre o relatório anual da administração, opinião sobre as propostas dos órgãos da administração, a serem submetidas à assembléia geral, relativas à modificação do capital social, emissão de debêntures ou bônus de subscrição, distribuição de dividendos, incorporação, fusão ou cisão, exame das demonstrações contábeis do exercício social e sobre elas opinar, entre outros.

O Comitê de Auditoria e o Conselho Fiscal estão em posições hierárquicas diferentes dentro de uma organização. O Comitê de Auditoria está subordinado e deve ser formado por membros do Conselho de Administração independentes e especialistas na área contábil/financeira. No caso de instituições financeiras e seguradoras, conforme definido na Resolução n. 3.198/ 2004, o Comitê de Auditoria pode ser formado por membros não integrantes do Conselho de Administração e, nesse caso, o Comitê não será subordinado a esse órgão.

Por sua vez, como já visto, o Conselho Fiscal é eleito pela Assembleia Geral, ou seja, é um órgão que representa os acionistas, inclusive os minoritários. Diferentemente do Comitê de Auditoria, o Conselho Fiscal é um órgão de instância societária, com previsão legal e é autônomo, pois não está vinculado a qualquer órgão de gestão da empresa.

Dessa forma, pode-se dizer que, enquanto o Comitê de Auditoria está relacionado com a administração da empresa, o Conselho Fiscal tem papel, praticamente, de fiscalização. O Conselho Fiscal, por não participar das decisões estratégicas da empresa, função que deve ser exercida pelo Conselho de Administração, pode não ter uma visão tão ampla da companhia, como é de se esperar do Comitê de Auditoria. Segundo o IBGC (2009a, p. 16), a empresa que 
optar pelo Conselho Fiscal adaptado precisa tomar cuidado para não atuar como orientador ou assessor de decisões da administração, ainda que algumas dessas decisões possam estar incluídas pela SEC entre aquelas próprias do Comitê de Auditoria como, por exemplo, aprovar a contratação de serviços de auditoria.

A SEC estabeleceu que as empresas estrangeiras que optarem por utilizar outro órgão para substituir o Comitê de Auditoria, como é o caso do Conselho Fiscal Adaptado no mercado brasileiro, as regras locais de independência podem ser mantidas; assim, no Brasil, prevalecem as regras estabelecidas na Lei $\mathrm{n}^{\circ} 6.404 / 76$.

O Comitê de Auditoria, conforme as regras da Sox, deve ser composto por membros independentes. No Brasil, se o Conselho Fiscal exercer a função de Comitê de Auditoria, apesar da permissão do uso de regras locais, a independência desse órgão pode não ser a mesma daquela imposta pelas regras norte-americanas, uma vez que o Conselho Fiscal, muitas vezes, é formado por representantes dos acionistas controladores e isso pode tornar sua independência dos acionistas questionável. Assim, caso a empresa opte pelo Conselho Fiscal adaptado, mesmo não sendo uma exigência da Sox, recomenda-se que seus membros sejam independentes.

As responsabilidades do Comitê de Auditoria são mais amplas que as do Conselho Fiscal. Segundo o IBGC (2009a, p. 16), aos Comitês de Auditoria estão afetas atividades próprias da função "administração": supervisão dos controles internos, avaliação dos riscos e supervisão de sua gestão, acompanhamento da atuação dos auditores independentes e supervisão dos trabalhos da auditoria interna. O foco é o preparo das demonstrações e informações financeiras para os investidores e o mercado (sem prejuízo do papel de fiscalização, que também é atribuído ao Conselho de Administração pela Lei das Sociedades Anônimas - S.A.). Como já visto, as atividades do Conselho Fiscal desenvolvem-se quase que no papel de ampla e irrestrita fiscalização por mandato dos acionistas, em decisão da Assembleia de Acionistas.

Deve-se destacar que a atuação do Conselho Fiscal adaptado, exercendo o papel de Comitê de Auditoria, decorre, exclusivamente, das exigências da SEC e da Sox. Segundo o IBGC (2009a, p. 16), é inadequado atribuir-se funções do Comitê de Auditoria ao Conselho Fiscal em qualquer outro âmbito. Em outras palavras, as empresas que operam no Brasil (por não estarem sujeitas às regras do mercado norte-americano) e, voluntariamente, pretendem formar o Comitê de Auditoria não deveriam exercer a opção de adaptar o seu Conselho Fiscal às funções do Comitê de Auditoria. 


\section{METODOLOGIA}

\subsection{Questionário}

O questionário é um importante e popular instrumento de coleta de dados para a pesquisa social. Trata-se de um conjunto ordenado e consistente de perguntas a respeito de variáveis e situações que se deseja medir ou descrever (MARTINS; THEÓPHILO, 2007, p. 90).

No questionário utilizado nesta pesquisa, foram elaboradas perguntas fechadas, abertas e de escala tipo Likert. As perguntas fechadas referem-se à opção da empresa por constituir Comitê de Auditoria ou Conselho Fiscal adaptado e quais os itens referentes às características das empresas que foram considerados na opção feita pela companhia. As perguntas abertas tiveram como objetivo obter as principais razões que levaram a empresa a optar pelo Comitê de Auditoria ou Conselho Fiscal adaptado. E as perguntas com as respostas em escala Likert consistiram em um conjunto de itens apresentados em forma de afirmações, em que se solicitou dos pesquisados que externassem sua reação, escolhendo um dos cinco pontos de uma escala (MARTINS; THEÓPHILO, 2007, p. 93).

Foi utilizado o teste de Alfa de Cronbach que, conforme Martins e Theóphilo (2007, p.13-15), testa a confiabilidade de instrumentos de coleta de dados e testes. O resultado de $81,4 \%$, maior que $70 \%$, indicou a confiabilidade das medidas.

O questionário passou por um pré-teste com 3 colaboradores e, em seguida, foi disponibilizado por meio do site da Fipecafi, que elabora questionários online para pesquisas realizadas por alunos de pós-graduação do Departamento de Contabilidade e Atuária da FEA USP. Com uma carta de introdução da pesquisa e o link do site do questionário online, foram contatadas 29 empresas, no período de maio a agosto de 2009.

No total, foram encaminhadas quatro remessas de emails tanto para os responsáveis pela área de relações com investidores quanto para a área de controladoria da empresa. Um novo contato foi feito, por meio de ligações telefônicas, para aquelas empresas que não haviam respondido ao questionário. Alguns respondentes solicitaram o questionário em arquivo eletrônico para posteriormente encaminharem as respostas. Foi informado aos respondentes que não seria feita qualquer associação entre os nomes das empresas e as respostas obtidas. No total das empresas contatadas, $52 \%$ responderam ao questionário. 


\subsection{Entrevistas}

Além das opiniões dos executivos das empresas, obtidas por meio de questionário, foram, também, colhidas as opiniões de conceituados analistas de mercado sobre a opção das empresas por formarem o Comitê de Auditoria ou utilizarem o Conselho Fiscal como Comitê de Auditoria. Segundo Martins e Theóphilo (2007, p. 86-87), a entrevista é uma técnica de pesquisa para a coleta de informações, dados e evidências cujo objetivo básico é entender e compreender o significado que entrevistados atribuem a questões e situações.

Foram contatados 6 analistas de mercado e de fato entrevistados 5 durante os meses de setembro e outubro de 2009. Devidamente autorizados por cada um deles, a seguir apresentase a lista desses analistas entrevistados: Harold Thau, Paulo Conte Vasconcellos, Paulo de Sá Pereira, Reginaldo Alexandre e Ricardo José de Almeida.

\section{APRESENTAÇÃO E ANÁLISE DOS RESULTADOS}

\subsection{Empresas analisadas}

Inicialmente, foi realizado levantamento de quantas empresas do mercado brasileiro possuíam ADRs no período de 31 de dezembro de 2002 a 31 de dezembro de 2009.

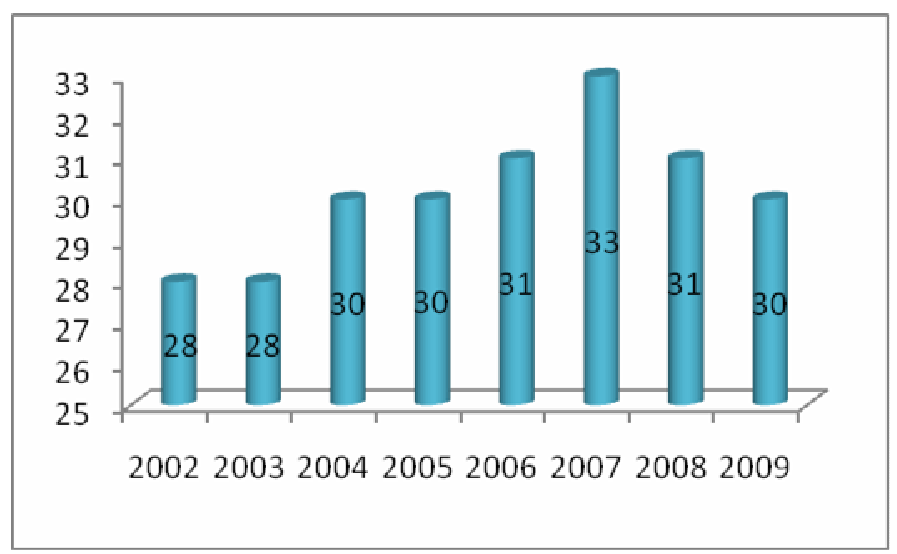

Gráfico 1 - Quantidade de entidades brasileiras na NYSE e NASDAQ no período de 2002 a 2009

Conforme Gráfico 1, o número de empresas e bancos brasileiros listados no mercado norte-americano aumentou de 28 em 2002 para 33 em 2007. Já em 2008, houve uma redução de duas entidades devido à fusão do Itaú com o Unibanco e a saída da Tele Norte Celular da NYSE, totalizando 31 entidades do mercado brasileiro na NYSE e NASDAQ. Em 2009, 
houve redução de uma empresa na NYSE, pois a Votorantim Papel e Celulose incorporou as ações da Aracruz Celulose surgindo a Fibria Celulose.

Nesta pesquisa, foram excluídos os bancos e a Telebrás que está isenta do arquivamento do 20-F devido ao seu reduzido número de acionistas.

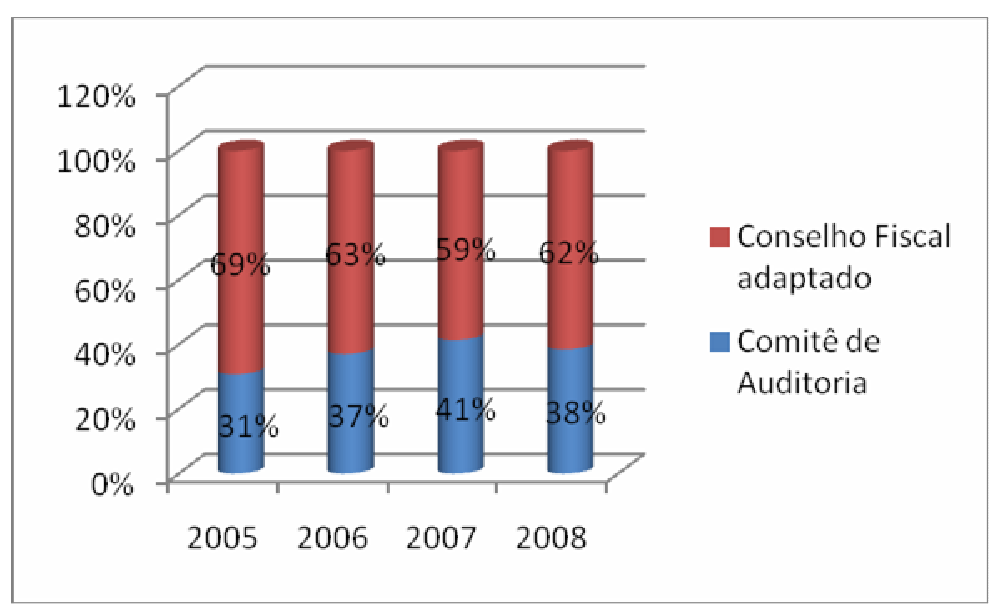

Gráfico 2 - Comitê de Auditoria x Conselho Fiscal adaptado

Conforme Gráfico 2, percebe-se que mais da metade das empresas brasileiras, no período de 2005 a 2008, preferiu apresentar um Conselho Fiscal com função de Comitê de Auditoria. As empresas da Bolsa de Valores Norte-Americana são classificadas conforme seu valor agregado de mercado (Aggregate Worldwide Market Value). O cálculo é feito com base no valor de mercado das ações (preço das ações multiplicado pela quantidade de ações em circulação), excluindo-se aquelas em poder de executivos da empresa e controladores e considerando-se as Bolsas de Valores de todos os países para os quais a empresa emite títulos. É possível ter a seguinte classificação conforme o arquivamento:

Grande, acelerado (Large Accelerated Filers): organização com valor agregado de mercado maior que US\$ 700 milhões;

$\checkmark \quad$ Acelerado (Accelerated Filers): organização com valor agregado de mercado entre US\$ 75 milhões e US\$ 700 milhões;

$\checkmark \quad$ Não acelerado (Non-Accelerated Filers): organização com valor agregado de mercado até US\$ 75 milhões.

A maioria das empresas brasileiras com ADRs que formaram o Comitê de Auditoria são classificadas como "Large Accelerated Filers" e, em 2007, 100\% das empresas estavam com essa classificação. Da mesma forma, das empresas que formaram o Comitê de Auditoria a maioria também foi classificada como "Large Accelerated Filer". Em relação aos auditores independentes, de 2005 a 2007, todas as empresas que formaram o Comitê de Auditoria foram 
auditadas por uma das Big 4. Em 2008, a Sadia foi a única empresa auditada por uma não Big 4. A maioria das empresas que formaram o Conselho Fiscal adaptado, igualmente, foi auditada por uma das Big 4.

\subsection{Resultados dos questionários e das entrevistas}

Do total das 29 empresas que fazem parte da pesquisa, 52\% responderam ao questionário, $10 \%$ informaram que não participariam da pesquisa por questões estratégicas, pela empresa não estar mais listada na NYSE e pela falta de tempo em atender à grande quantidade de pesquisas e questionários recebidos diariamente. Além dessas, $38 \%$ das empresas para as quais foram enviados questionários não prestaram qualquer informação.

Assim, os resultados obtidos e apresentados a seguir foram baseados nas respostas fornecidas por executivos de 15 empresas que se disponibilizaram a participar da pesquisa: Aracruz Celulose, Brasil Food, Brasil Telecom, Cemig, Copel, Embraer, Gerdau, Net Serviços de Comunicação, Petrobrás, Sabesp, TAM, Telefônica, Tele Norte Celular, Vale e VCP.

Levando-se em consideração as empresas que participaram do estudo, $60 \%$ utilizam o Conselho Fiscal adaptado e até hoje o mantém, enquanto os outros $40 \%$ estão com o Comitê de Auditoria. As principais razões apontadas pelos executivos das empresas que optaram por utilizar o Conselho Fiscal Adaptado e até hoje o mantém foram:

$\checkmark \quad$ Evitar a criação de uma nova estrutura, uma vez que a empresa possui um Conselho Fiscal muito atuante, adequadamente formado e capaz de atuar como agente fiscalizador dos atos praticados pela Companhia;

$\checkmark \quad$ Evitar a superposição de funções com a estrutura de Comitês de Assessoramento já existentes;

$\checkmark \quad$ O Conselho Fiscal da companhia já se preocupava com os controles internos e com a gestão de riscos corporativos;

$\checkmark \quad$ Possibilitar uma maior transparência ao processo de Governança Corporativa adotado pela Companhia e consequente credibilidade ao Comitê formado já que esse é independente da Administração e também representa os acionistas minoritários, atendendo, em parte, as duas legislações, uma vez que faz papel de fiscalizador das decisões tomadas pela empresa;

$\checkmark \quad$ Maior conhecimento e discussões prévias com os membros do Conselho Fiscal de questões relacionadas a controles internos e divulgação de informações;

Menores custos além de ser a cultura do grupo de que a empresa faz parte. 
Os executivos das empresas que optaram por formar o Comitê de Auditoria justificaram essa alternativa da seguinte forma:

$\checkmark \quad$ Preocupação em atender totalmente às exigências da Sox;

$\checkmark$ Adoção das Melhores Práticas de Governança Corporativa;

Alinhamento com o Acionista Controlador que também possui Comitê de Auditoria;

$\checkmark \quad$ Necessidade de uma pessoa com profundo conhecimento técnico financeiro para avaliação das demonstrações contábeis da companhia;

$\checkmark \quad$ A empresa já tinha um Comitê de Auditoria desde 1997 e formou o Conselho Fiscal por volta de 2002, a pedido de sócios minoritários. Ambos têm atuação independente, apesar de realizarem algumas reuniões conjuntas. Com a publicação da Sox, o Comitê de Auditoria sofreu alguns ajustes, entre eles a designação do especialista financeiro, sendo ambos mantidos até então.

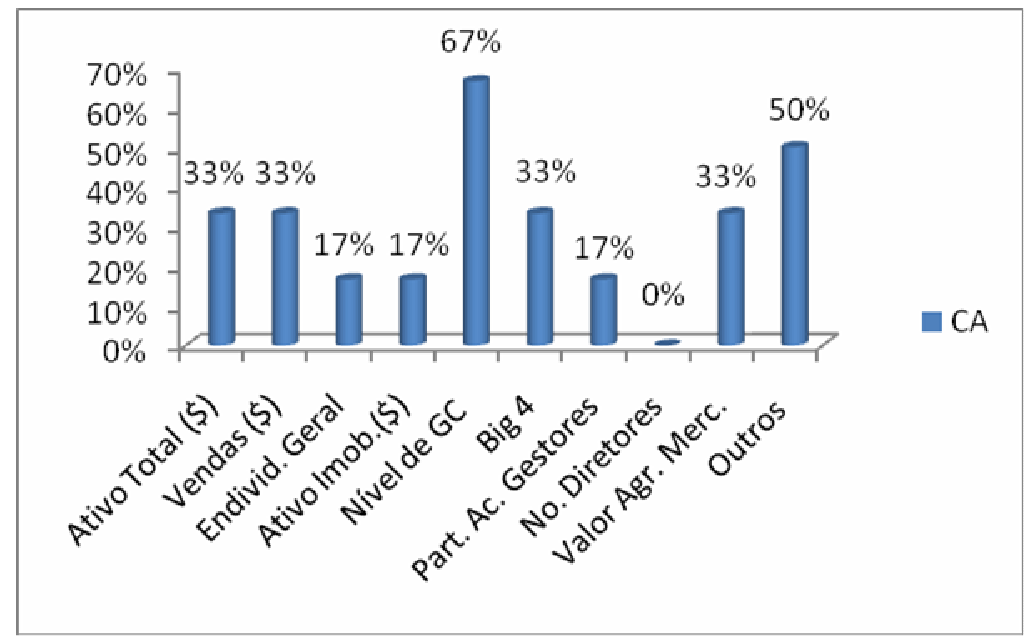

Gráfico 3 - Itens considerados na opção por formar o Comitê de Auditoria

Posteriormente, os executivos das empresas foram questionados sobre quais dos itens apresentados influenciaram a empresa na escolha por formar o Comitê de Auditoria ou utilizar o Conselho Fiscal adaptado.

O Gráfico 3 mostra que a maioria (67\%) dos executivos das empresas entende que a opção pela formação do Comitê de Auditoria foi fortemente influenciada pelo acréscimo no nível de governança corporativa da empresa. Os "outros" fatores que foram assinalados por $50 \%$ dos executivos das empresas referem-se às seguintes razões: certificações do Diretor Presidente e do Diretor de Finanças no Relatório 20-F; criação de um Comitê Permanente de Divulgação e o alinhamento com o acionista controlador que formou o Comitê de Auditoria. 
Nenhum desses executivos considerou importante o número de diretores na escolha pelo Comitê de Auditoria.

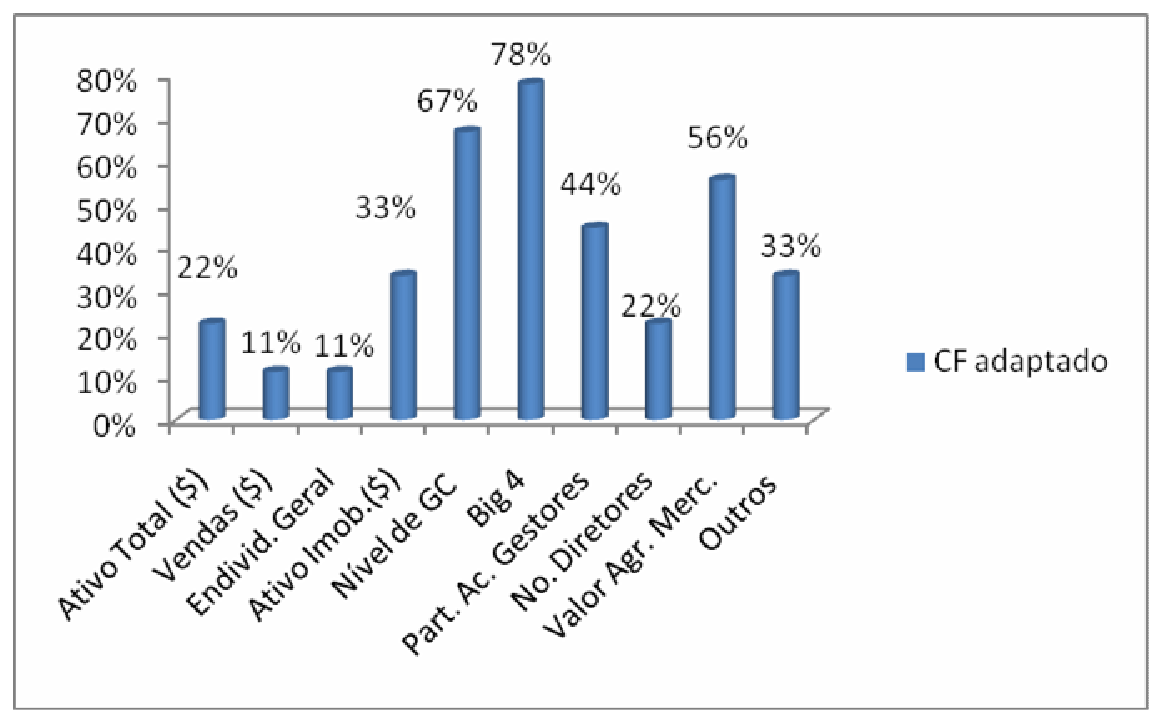

Gráfico 4 - Itens considerados na opção por utilizar o Conselho Fiscal adaptado

Igual questionamento foi feito aos executivos das empresas que optaram pelo Conselho Fiscal adaptado e 78\% apontaram que a empresa ser auditada por uma das Big 4 influenciou a escolha, conforme o Gráfico 4. Outros fatores que também foram indicados pela maioria dos executivos das empresas: nível de governança corporativa da empresa $(67 \%)$ e valor agregado de mercado $(56 \%)$.

Os "outros" itens considerados por $33 \%$ dos executivos incluem: evitar a criação de uma nova estrutura, uma vez que o Conselho Fiscal da empresa é muito atuante e capaz de atuar como agente fiscalizador dos atos praticados pela Companhia; existência de Comitês de Assessoramento; conhecimento dos conselheiros sobre controles internos e relatórios financeiros e atendimento a padrões de governança diferenciados de países nos quais a empresa tem ações negociadas.

Em relação às entrevistas realizadas, todos os 5 analistas de mercado entrevistados são homens, sendo que 4 possuem acima de 46 anos e 1 entre 36 e 40 anos. As entrevistas foram feitas por telefone e consistiram em duas perguntas abertas e sete perguntas fechadas; essas últimas foram feitas na forma de avaliação de afirmações sobre Comitê de Auditoria e Conselho Fiscal adaptado. As respostas foram anotadas por escrito e o tempo médio de cada entrevista foi de 25 minutos.

No que diz respeito à formação acadêmica, um é graduado em economia, dois são administradores de empresa, sendo que um deles tem curso de pós-graduação, um é mestre 
em Administração e um é doutor em Administração. A média de tempo de experiência profissional é de 25 anos e os cargos ocupados pelos entrevistados são: Presidente da associação que congrega os analistas de mercado de São Paulo, membro do Comitê de Pronunciamentos Contábeis (CPC), Assessor empresarial; Conselheiro da Administração de quatro empresas, sócio de uma empresa de consultoria empresarial; Gerente executivo; Sócio diretor de empresa de treinamento; Analista de mercado de capitais.

Segundo os entrevistados, as razões que levaram as empresas a optarem por formar o Comitê de Auditoria ou utilizar o Conselho Fiscal adaptado foram:

- Devido à demanda da Sox, no primeiro momento as empresas que já possuíam um Conselho Fiscal resolveram utilizar o Conselho Fiscal adaptado. Hoje, pela legislação e circunstância, é comum as empresas terem ao mesmo tempo o Conselho Fiscal e o Comitê de Auditoria.

- Há uma preocupação das empresas com a imagem externa e com o IBGC. A escolha do Comitê de Auditoria ou Conselho Fiscal adaptado está vinculada com a governança corporativa e a redução dos riscos empresariais. Na Lei das S/As não há a figura do Comitê de Auditoria e sim do Conselho Fiscal. Com a evolução do conceito de governança corporativa foram criados vários comitês: de compliance, risco etc..

- As exigências dos acionistas minoritários e a governança corporativa fazem com que haja necessidade de se criar o Comitê de Auditoria ou adaptar o Conselho Fiscal a essa função.

- A questão do custo. Por exemplo, a Previ é uma grande investidora e ela exige a presença de um Conselho Fiscal nas empresas em que participa (que é investidora). Assim, para essas empresas haveria um custo adicional de formar um Comitê de Auditoria, por isso acabam formando o Conselho Fiscal adaptado. Todavia, para as empresas que não têm Conselho Fiscal é mais interessante formar Comitê de Auditoria. No Brasil, o Comitê de Auditoria é formado, na maioria das vezes, por membros do Conselho de Administração da empresa ou por membros da Diretoria que já possuem uma remuneração na empresa e, assim, se fizerem também parte do Comitê de Auditoria o adicional da remuneração que será pago é mais baixo para as empresas.

- As mudanças das práticas contábeis, incluindo IFRS e debates de "como fazer da maneira correta” tornam o Comitê de Auditoria ou Conselho Fiscal adaptado importantes na disseminação de conhecimentos na empresa e contribuirão de forma efetiva para a gestão. 
Posteriormente, foram solicitados os argumentos prós e contras da implantação do Comitê de Auditoria ou da adaptação do Conselho Fiscal. Os pontos positivos comentados pelos analistas de mercado sobre o Comitê de Auditoria foram:

- É um órgão de gestão e não se limita a fiscalizar, ele pode opinar e dar sugestões. $O$ Comitê de Auditoria tem um papel mais amplo que o Conselho Fiscal. O Conselho Fiscal é mais um órgão vinculado ao exame das contas, enquanto o Comitê de Auditoria está vinculado ao conceito de exposição ao risco, ele vê diferentes áreas na empresa para não haver exposição ao risco de desvio de conduta.

- Se a empresa tem Conselho Fiscal (mas não o Conselho Fiscal adaptado), ela precisa então formar o Comitê de Auditoria. O Conselho Fiscal puro é insuficiente e as práticas contábeis estão aumentando seu nível de complexidade e precisam de um Comitê de Auditoria ou Conselho Fiscal adaptado, além do risco de agência que existe na empresa já que os executivos muitas vezes podem tentar maximizar sua própria rentabilidade ao invés de maximizar a rentabilidade da empresa.

- O Comitê de Auditoria tem melhor orçamento e melhores condições para fazer avaliações que o Conselho Fiscal puro.

Já os pontos negativos citados sobre Comitê de Auditoria foram:

- O Comitê de Auditoria não tem representação dos acionistas minoritários, que estão sempre atentos aos fatos que ocorrem na empresa e assim o Comitê de Auditoria pode sofrer maior pressão que o Conselho Fiscal.

- Dificuldade de se fazer uma composição do Comitê de Auditoria totalmente isenta da gestão. A independência do Comitê de Auditoria é prejudicada no Brasil porque o número de conselheiros externos e independentes no Comitê de Auditoria é relativamente pequeno. Geralmente, o Comitê de Auditoria é formado por membros da própria gestão da empresa (Conselho de Administração e Diretoria) e poucos especialistas financeiros externos.

- Do ponto de vista prático, se a empresa já tem um Conselho Fiscal, então é mais vantajoso criar o Conselho Fiscal adaptado, pois a formação do Comitê de Auditoria é mais um órgão que aumenta a burocracia na empresa.

- O Comitê de Auditoria é subordinado ao Conselho de Administração que pode favorecer os acionistas majoritários, ou seja, o Comitê de Auditoria pode garantir que as decisões tomadas não sejam diferentes das esperadas pelos controladores. 
Em seguida, os analistas de mercado foram questionados sobre quais seriam os aspectos positivos e negativos do Conselho Fiscal adaptado. Os pontos positivos levantados do Conselho Fiscal adaptado foram:

- É um órgão independente. Em situações de abuso por parte dos acionistas controladores, o Conselho Fiscal defende os interesses dos acionistas minoritários. Além disso, devido à sua independência, o Conselho Fiscal dá conforto ao Conselho de Administração. Assim, o Conselho Fiscal turbinado tem mais instrumento/poder de dar tranquilidade para o Conselho de Administração.

- O Conselho Fiscal tem competência para exercer as funções do Comitê de Auditoria. Se existir o Comitê de Auditoria e Conselho Fiscal na empresa pode haver conflito entre ambos e superposição de funções em relação aos objetivos que eles têm em comum.

- O Conselho Fiscal, com o mesmo orçamento do Comitê de Auditoria, poderia fazer as mesmas coisas que o Comitê de Auditoria (não há necessidade de criar Comitê de Auditoria).

Com relação aos pontos negativos do Conselho Fiscal adaptado, foram obtidas as seguintes respostas:

- Os críticos afirmam que o Conselho Fiscal não tem exercido corretamente seu papel devido à falta de formação técnica de seus representantes para questionamentos e análises, além da desatenção desses profissionais, ou seja, havia no passado uma má escolha do representante do Conselho Fiscal.

- Quando a empresa tem Comitê de Auditoria, auditoria interna e uma boa auditoria externa, o Conselho Fiscal não agrega nada. O Conselho Fiscal perde o sentido quando tudo é feito corretamente.

- As empresas optam pelo Conselho Fiscal adaptado pelo seu histórico/antecedente. O Conselho Fiscal está focado no exame das Demonstrações Contábeis ou quando há alguma dúvida específica. Está ligado ao controle acionário da empresa e tem limitações de atuação. Já o Comitê de Auditoria tem função ampliada e pode investigar de forma mais profunda determinados assuntos.

Uma observação feita por um dos entrevistados é que o Comitê de Auditoria e o Conselho Fiscal são complementares, um não é melhor ou pior que o outro. O Comitê de Auditoria pode ter pessoas com capacitação técnica melhor que o Conselho Fiscal, porém não 
tem a independência e autonomia do Conselho Fiscal (e essa é a diferença fundamental entre os dois órgãos), por isso que um complementa o outro.

Na sequência, foi solicitado aos executivos das empresas e aos analistas de mercado para que avaliassem algumas afirmações sobre o Comitê de Auditoria e o Conselho Fiscal adaptado. Sobre as funções do Comitê de Auditoria, foram feitas as seguintes afirmações:

Afirmação 1: As atribuições do Conselho Fiscal adaptado e o Comitê de Auditoria são distintas.

Tabela 1 - Respostas da afirmação 1

\begin{tabular}{lccccc}
\hline & $\begin{array}{l}\text { Concordo } \\
\text { plenamente }\end{array}$ & \multicolumn{2}{l}{$\begin{array}{l}\text { Corcondo em Não concordo } \\
\text { parte }\end{array}$} & $\begin{array}{l}\text { Discordo em } \\
\text { nem discordo }\end{array}$ & $\begin{array}{l}\text { Discordo } \\
\text { plenamente }\end{array}$ \\
\hline \hline $\begin{array}{l}\text { Executivos das } \\
\text { empresas }\end{array}$ & $20 \%$ & $27 \%$ & - & $47 \%$ & $6 \%$ \\
\hline $\begin{array}{l}\text { Analistas de } \\
\text { mercado }\end{array}$ & $40 \%$ & $60 \%$ & - & - & - \\
\hline
\end{tabular}

Os resultados encontrados na Tabela 1 mostram que 47\% dos executivos das empresas discordaram em parte dessa afirmação e $6 \%$ discordaram plenamente, enquanto $27 \%$ concordaram em parte, $20 \%$ concordaram plenamente. Percebe-se que pouco mais da metade dos executivos das empresas acredita que, de certa forma, as funções do Conselho Fiscal adaptado e Comitê de Auditoria não são tão distintas.

Ao contrário do resultado obtido quando se perguntou aos executivos das empresas, a maioria dos analistas de mercado concordou que, de certa forma, as funções dos dois órgãos não são semelhantes. Os que concordaram plenamente alegaram que há certas decisões como, por exemplo, o processo de contratação, seleção e monitoramento da auditoria externa, que o Conselho Fiscal não faz, enquanto o Comitê de Auditoria participa dessa decisão. Além disso, de acordo com a Lei das S.A., eles são diferentes. O Comitê de Auditoria está relacionado a questões históricas e surgiu devido a fraudes. O Conselho Fiscal opina na política de dividendos que é uma expectativa do futuro, por exemplo.

Já os analistas, que concordaram em parte, afirmaram que o Conselho Fiscal adaptado continua sendo um Conselho Fiscal, que é um órgão de instância societária, independente e autônomo, enquanto o Comitê de Auditoria não representa uma instância societária. Outro ponto destacado pelos entrevistados foi que o Conselho Fiscal adaptado tem função de 
Conselho Fiscal e Comitê de Auditoria e que o Comitê de Auditoria tem funções mais ampliadas que o Conselho Fiscal adaptado.

Afirmação 2: O Comitê de Auditoria pode ser visto como um mecanismo de monitoramento da gestão da empresa.

Tabela 2 - Respostas da afirmação 2

\begin{tabular}{lccccc}
\hline & $\begin{array}{l}\text { Concordo } \\
\text { plenamente }\end{array}$ & \multicolumn{2}{l}{$\begin{array}{l}\text { Corcondo em Não concordo } \\
\text { parte }\end{array}$} & $\begin{array}{l}\text { Discordo em } \\
\text { nem discordo }\end{array}$ & $\begin{array}{l}\text { Discordo } \\
\text { plenamente }\end{array}$ \\
\hline \hline $\begin{array}{l}\text { Executivos das } \\
\text { empresas }\end{array}$ & $60 \%$ & $33 \%$ & - & - & $7 \%$ \\
\hline $\begin{array}{l}\text { Analistas de } \\
\text { mercado }\end{array}$ & $60 \%$ & $40 \%$ & - & - & - \\
\hline
\end{tabular}

Ao analisar o papel do Comitê de Auditoria como mecanismo de monitoramento da gestão da empresa, 60\% dos executivos concordaram plenamente com essa afirmação, enquanto $33 \%$ concordaram em parte e somente $7 \%$ discordaram totalmente, conforme Tabela 2. Dessa forma, o resultado indica que a maioria dos executivos das empresas acredita que o Comitê de Auditoria pode ser visto como um mecanismo de monitoramento.

Assim como os executivos das empresas, a maioria dos analistas (60\%) concordou plenamente com a afirmação, enquanto os demais concordaram em parte. Dentre aqueles que concordaram plenamente, uma das justificativas foi a de que o Comitê de Auditoria tem papel importante para acompanhar o controle da empresa e pode dar um suporte mais adequado ao Conselho Fiscal. Assim, o trabalho do Comitê de Auditoria soma-se ao do Conselho Fiscal. Além disso, o Comitê de Auditoria faz monitoramento quanto a controles internos, processo de risco e alguns atos da gestão.

Uma observação feita por um dos analistas de mercado é que, mesmo sendo o Comitê de Auditoria um mecanismo de monitoramento, o principal órgão encarregado dessa função na gestão da empresa é o Conselho de Administração e o Comitê de Auditoria está a ele subordinado.

Os que concordaram em parte afirmaram que o Comitê de Auditoria monitora os números e que esse órgão está subordinado ao Conselho de Administração e, dessa forma, certifica aquilo que o Conselho de Administração deseja. Assim, o Comitê de Auditoria pode não monitorar, de forma adequada, a gestão da empresa e abrir uma lacuna para o aparecimento de conflitos de interesses. 
Para a avaliação da influência dos custos na opção de se formar o Comitê ou utilizar o Conselho Fiscal adaptado, foi feita a seguinte afirmação:

Afirmação 3: A utilização do Conselho Fiscal adaptado em substituição ao Comitê de Auditoria poupa custos para a empresa.

Tabela 3 - Respostas da afirmação 3

\begin{tabular}{|c|c|c|c|c|c|}
\hline & $\begin{array}{l}\text { Concordo } \\
\text { plenamente }\end{array}$ & $\begin{array}{l}\text { Corcondo em } \\
\text { parte }\end{array}$ & $\begin{array}{l}\text { Não concordo } \\
\text { nem discordo }\end{array}$ & $\begin{array}{l}\text { Discordo em } \\
\text { parte }\end{array}$ & $\begin{array}{l}\text { Discordo } \\
\text { plenamente }\end{array}$ \\
\hline $\begin{array}{l}\text { Executivos das } \\
\text { empresas }\end{array}$ & $13 \%$ & $34 \%$ & $13 \%$ & $13 \%$ & $27 \%$ \\
\hline $\begin{array}{l}\text { Analistas de } \\
\text { mercado }\end{array}$ & $40 \%$ & - & $20 \%$ & $40 \%$ & - \\
\hline
\end{tabular}

Conforme a Tabela 3, 34\% dos executivos das empresas concordaram em parte e 13\% concordaram totalmente. Já os executivos das empresas que discordaram plenamente dessa afirmação totalizam $27 \%$, os que discordaram em parte são $13 \%$ e aqueles que não discordaram nem concordaram, os $13 \%$ restantes.

Não houve consenso nas respostas obtidas dos analistas de mercado, sendo que $40 \%$ concordaram plenamente com a afirmação, enquanto $20 \%$ não concordaram nem discordaram e $40 \%$ discordaram em parte. Os que concordaram plenamente alegaram que o Conselho Fiscal já tem o expertise para exercer as funções do Comitê de Auditoria. O que não concorda nem discorda acredita que os custos dependerão de a empresa já ter ou não um Conselho Fiscal.

Os que discordam em parte acreditam que os custos são próximos e o Conselho Fiscal não tem uma remuneração muito alta. Assim, consideraram que esse é um item não relevante. Outro argumento é que os custos dependerão das funções, remunerações dos diferentes órgãos e dos profissionais que formarão o Comitê de Auditoria.

Como a SEC possibilitou que, no Brasil, o Conselho Fiscal pudesse ser adaptado para exercer as funções do Comitê de Auditoria, os executivos das empresas tiveram que avaliar a seguinte afirmação:

Afirmação 4: O Conselho Fiscal adaptado que atua com funções de Comitê de Auditoria é mais adaptável ao ambiente de negócios brasileiros do que a formação do Comitê de Auditoria conforme a Sox e SEC. 
Tabela 4 - Respostas da afirmação 4

\begin{tabular}{lccccc}
\hline & $\begin{array}{l}\text { Concordo } \\
\text { plenamente }\end{array}$ & \multicolumn{2}{c}{$\begin{array}{l}\text { Corcondo em Não concordo } \\
\text { parte }\end{array}$} & $\begin{array}{l}\text { Discordo em } \\
\text { pem discordo }\end{array}$ & $\begin{array}{l}\text { Discordo } \\
\text { plenamente }\end{array}$ \\
\hline \hline $\begin{array}{l}\text { Executivos das } \\
\text { empresas }\end{array}$ & $13 \%$ & $53 \%$ & - & $7 \%$ & $27 \%$ \\
\hline $\begin{array}{l}\text { Analistas de } \\
\text { mercado }\end{array}$ & $40 \%$ & - & $60 \%$ & - & - \\
\hline
\end{tabular}

Os resultados da Tabela 4 mostram que 53\% dos executivos das empresas concordaram em parte com essa afirmação e $13 \%$ concordaram plenamente. Em contraposição, $27 \%$ dos executivos discordaram totalmente e $7 \%$ discordaram em parte.

Dentre os analistas de mercado, $60 \%$ não concordaram nem discordaram com a afirmação e $40 \%$ concordaram plenamente. Os que não concordaram nem discordaram alegaram que o Comitê de Auditoria é um órgão de apoio especializado e é complementar ao Conselho Fiscal, que é um órgão de representação societária. Dessa forma, o Comitê de Auditoria e o Conselho Fiscal deveriam trabalhar em conjunto e não um ou outro.

Além disso, para as empresas que já possuem Conselho Fiscal, o Conselho Fiscal adaptado se adequa melhor à empresa. Para as que não têm Conselho Fiscal é melhor criar Comitê de Auditoria.

Os que concordaram plenamente disseram que a formação do Comitê de Auditoria, conforme as regras da Sox, exige que os conselheiros sejam independentes e o número de empresas com conselheiros independentes no Brasil é pequeno. Isso ocorre devido a uma dificuldade prática e, dessa forma, no Brasil o Comitê de Auditoria ainda não preenche todos os requisitos estabelecidos pela Sox.

Também foi destacado que o Conselho Fiscal tem toda condição de atuar como Comitê de Auditoria, pois detém maior conhecimento, comprometimento e envolvimento da empresa. O Comitê de Auditoria tem baixa credibilidade, pois é vinculado ao Conselho de Administração e não garante a independência, enquanto o Conselho Fiscal, exatamente por manter-se independente, tem alta credibilidade.

Por fim, os executivos das empresas e analistas de mercado avaliaram a afirmação:

Afirmação 5: No Brasil, faltam executivos que se enquadrem no Comitê de Auditoria, conforme definido pela SEC e Sox, no que diz respeito à independência de seus membros e à presença de um especialista financeiro. 
Tabela 5 - Respostas da afirmação 5

\begin{tabular}{lccccc}
\hline & $\begin{array}{l}\text { Concordo } \\
\text { plenamente }\end{array}$ & \multicolumn{2}{c}{$\begin{array}{l}\text { Corcondo em Não concordo } \\
\text { parte }\end{array}$} & $\begin{array}{l}\text { Discordo em } \\
\text { pem discordo }\end{array}$ & $\begin{array}{l}\text { Discordo } \\
\text { plenamente }\end{array}$ \\
\hline \hline $\begin{array}{l}\text { Executivos das } \\
\text { empresas }\end{array}$ & $7 \%$ & $20 \%$ & - & $33 \%$ & $40 \%$ \\
\hline $\begin{array}{l}\text { Analistas de } \\
\text { mercado }\end{array}$ & $20 \%$ & - & $20 \%$ & - & $60 \%$ \\
\hline
\end{tabular}

Os resultados da Tabela 5 indicam que $40 \%$ dos executivos das empresas discordaram totalmente da afirmação e outros 33\% discordaram em parte. Apenas $7 \%$ dos executivos concordaram plenamente e $20 \%$ concordaram em parte.

A maioria dos analistas de mercado (60\%) discordou totalmente da afirmação, enquanto $20 \%$ concordaram plenamente, e os outros $20 \%$ não concordaram nem discordaram. O analista que concordou plenamente afirmou que há escassez de profissionais e que os profissionais não estão adaptados às regras internacionais de contabilidade e auditoria; complementou manifestando a opinião de que os que têm esse conhecimento estão alocados em consultorias ou empresas de auditoria.

O analista que não concordou nem discordou comentou que não faltam executivos com esse perfil. O que ocorre é a falta de cultura. Muitas empresas têm controle definido e os controladores querem ser maioria no Conselho de Administração e não deixam que os conselheiros independentes façam parte.

Por fim, os que discordaram plenamente alegaram que, no Brasil, há profissionais altamente qualificados que podem exercer ambas as funções. Segundo a opinião desses analistas, a questão não é a falta de profissionais e, sim, o desejo de se querer colocar ou não esses executivos no Comitê.

\section{CONCLUSÕES}

A exceção dada pela SEC à regra 10A-3 às empresas que operam no Brasil e têm seus títulos negociados no mercado norte-americano permitiu que tais empresas pudessem formar o Comitê de Auditoria ou adaptar as funções do Conselho Fiscal às do Comitê de Auditoria. O objetivo desta pesquisa foi obter as opiniões e percepções dos analistas de mercado e dos executivos das empresas acerca da formação do Comitê de Auditoria ou da utilização do Conselho Fiscal adaptado. 
Todas as empresas que operam no Brasil e que têm seus títulos negociados no mercado de valores dos Estados Unidos da América foram contatadas para participar da pesquisa e $52 \%$ responderam ao questionário. Dessa forma, a análise dos resultados baseia-se nas respostas fornecidas pelos executivos dessas empresas. As entrevistas com os analistas de mercado foram feitas com uma amostra intencional e não probabilística. Assim, as opiniões obtidas ficam restritas às percepções dessas pessoas.

Os resultados indicam que a maioria das empresas que formaram o Comitê de Auditoria considerou o nível de governança corporativa na decisão de formar o Comitê ou adaptar o Conselho Fiscal às funções do Comitê de Auditoria. Outros fatores, tais como as certificações do Diretor Presidente e do Diretor de Finanças no relatório 20-F, também foram importantes na tomada dessa decisão.

Por outro lado, as empresas que utilizaram o Conselho Fiscal adaptado afirmaram que o fato de ser auditada por uma das Big 4 foi um fator preponderante na escolha de um ou outro órgão, além do nível de governança corporativa e valor agregado de mercado.

Para os analistas de mercado, as razões que levaram as empresas a optarem por formar o Comitê de Auditoria ou Conselho Fiscal adaptado foram as seguintes: imagem da empresa no mercado, governança corporativa, redução do risco, direito dos acionistas minoritários, custo de formação do Comitê e mudanças nas práticas contábeis.

Tanto a maioria dos executivos das empresas quanto dos analistas de mercado concordaram plenamente que o Comitê de Auditoria pode ser visto como um mecanismo de monitoramento da gestão da companhia e discordaram que, no Brasil, faltem profissionais com perfil que se enquadre nas exigências para formação do Comitê de Auditoria, conforme definido pela SEC.

Todavia, percebe-se que, para alguns dos principais aspectos envolvendo a formação do Comitê de Auditoria ou a adaptação das funções do Conselho Fiscal às do Comitê de Auditoria, as percepções dos analistas de mercado e dos executivos das empresas que tiveram que se subordinar às regras impostas pela Sox são divergentes e até contraditórias.

Assim, este trabalho pretendeu contribuir para o estudo, no mercado brasileiro, da implantação do Comitê de Auditoria ou adaptação do Conselho Fiscal já instalado. Sugere-se para pesquisas posteriores analisar as empresas que não estão sujeitas à Sox e que, voluntariamente, formaram o Comitê de Auditoria. 


\section{Referências}

ADAMS, M. Determinants of audit committee formation in the life insurance industry: New Zealand evidence. Journal of Business Research. New York, v. 38, p. 123, Feb. 1997.

BRADBURY, M. E. The incentives for voluntary audit committee formation. Journal of Accounting and Public Policy. [S.1.], v. 9, p. 19-36, 1990.

BRAIOTTA, L. Jr. The audit director`s guide. New York: John Willey \& Sons, 1981.

BRASIL. Lei 11.638, de 28/12/2007. Disponível em: <http://www.planalto.gov.br>. Acesso em: 10 abril 2009.

CHOW, C. W. The demand of external auditing: size, debt and ownership influences. The Accounting Review. [S.1.], v. 52, p. 272-291, 1982.

COLLIER, P. Factors affecting the formation of audit committees in major UK listed companies. Accounting and Business Research. Kingston Upon Thames, v. 23, p. 421, 1993.

COLLIER, P.; GREGORY, A. Audit committee activity and agency costs. Journal of Accounting and Public Policy. [S.1.], v. 18, p. 311-332, Winter. 1999.

FAMA, E. F.; JENSEN, M. C. Agency problems and residual claims. The Journal of Law and Economics. [S.1.], 1983.

FELO, A. J.; KRISHNAMURTHY, S.; SOLIERI, S. A. Audit committee characteristics and the perceived quality of financial reporting: an empirical analysis. Apr. 2003. Disponível em: $<$ http://ssrn.com/abstract=401240> or DOI: <10.2139/ssrn.401240>. Acesso em: 26 jun. 2009.

IBGC. Instituto Brasileiro de Governança Corporativa. Guia de orientações para melhores práticas de Comitês de Auditoria. Coordenação: Roberto Lamb e João Verner Juenemann. São Paulo: IBGC, 2009a.

JENSEN, M. C.; MECKLING, W. Theory of the firm: managerial behavior, agency cost and capital structure. Journal of Financial Economics (JFE). [S.1.], v. 3, n. 4, 1976.

MARTINS, G. A.; THEÓPHILO, C. R. Metodologia da investigação científica para as ciências sociais aplicadas. São Paulo: Atlas, 2007.

MENON, K.; WILLIAMS, J. D. The use of audit committee for monitoring. Journal of Accounting and Public Policy. [S.1.], v. 13, p. 121-139, 1994.

PINCUS, K.; RUSBARSKY, M.; WONG, J. Voluntary formation of corporate audit committees among NASDAQ firms. Journal of Accounting and Public Policy. [S.1.], 1989.

PIOT, C. The existence and independence of audit committees in France. Accounting and Business Research. United Kingdom, v. 34, n. 3, p. 223-246, 2004. 
RAINSBURY, E. A.; BRADBURY, M. E.; CAHAN, S. F. Firm characteristics and audit committees complying with 'best practice' membership guidelines. Accounting and Business Research. United Kingdom, v. 38, n. 5, p. 393-408, 2008.

TURLEY, S.; ZAMAN, M. The corporate governance effects of audit committees. Journal of Management and Governance. [S.1.], v. 8, n. 3, p. 305-332, 2004. Disponível em: <www.ssrn.com>. Acesso em: 15 out. 2008.

WATTS, R. L.; ZIMMERMAN, J. L. Positive accounting theory. Englewood Cliffs, N.J.: Prentice Hall, 1986. 